Article

\title{
Wireless Battery Charging Circuit Using Load Estimation without Wireless Communication
}

\author{
Sang-Won Lee ${ }^{1}{ }^{\circledR}$, Yoon-Geol Choi ${ }^{2}$, Jung-Ha Kim ${ }^{1}$ and Bongkoo Kang ${ }^{1, *}$ \\ 1 Department of Electrical Engineering, Pohang University of Science and Technology, Pohang, \\ Kyungpook 37673, Korea; sangwony1@postech.ac.kr (S.-W.L.); jungha@postech.ac.kr (J.-H.K.) \\ 2 LS Industrial Systems R\&D Campus, LS-ro 116 beongil 40, Dongan-gu, Anyang-si, Gyeonggi-do 14118, \\ Korea; ygchoi2@lsis.com \\ * Correspondence: bkkang@postech.ac.kr; Tel.: +82-54-279-5939
}

Received: 15 October 2019; Accepted: 21 November 2019; Published: 25 November 2019

check for updates

\begin{abstract}
A wireless battery charging circuit is proposed, along with a new load estimation method. The proposed estimation method can predict the load resistance, mutual inductance, output voltage, and output current without any wireless communication between the transmitter and receiver sides. Unlike other estimation methods that sense the high-frequency AC voltage and current of the transmitter coil, the proposed method only requires the DC output value of the peak current detection circuit at the transmitter coil. The proposed wireless power transfer (WPT) circuit uses the estimated parameters, and accurately controls the output current and voltage by adjusting the switching phase difference of the transmitter side. The WPT prototype circuit using a new load estimation method was tested under various coil alignment and load conditions. Finally, the circuit was operated in a constant current and constant voltage modes to charge a $48-\mathrm{V}$ battery pack. These results show that the proposed WPT circuit that uses the new load estimation method is well suited for charging a battery pack.
\end{abstract}

Keywords: wireless power transfer (WPT) circuit; battery charger; load estimation; constant current (CC) charging; constant voltage (CV) charging

\section{Introduction}

Wireless power transfer (WPT) technologies have been rapidly developed and widely applied to many industrial applications, such as biomedical devices, consumer electronics, manufacturing facilities, and electric vehicles (Evs), where direct contact between power supplies and applications is impossible or inconvenient [1-4]. To efficiently transfer power, most of the WPT circuits use electromagnetic coupling between coils. These WPT circuits use capacitors to reduce reactive power [5-13], and can be largely categorized into four types, depending on whether the capacitors are connected with the transmitter and receiver coils in series and series (S-S), series and parallel (S-P), parallel and parallel (P-P), or parallel and series (P-S) [5-7]. Among them, the S-S circuit has been widely used because the capacitances can be chosen independently of the load and coupling conditions [7-10].

A typical S-S WPT circuit (Figure 1) $[7,9,10]$ consists of a full-bridge inverter $\left(Q_{1}-Q_{4}\right)$, a transmitter coil $\left(L_{1}\right)$, a full-bridge rectifier $\left(D_{1}-D_{4}\right)$, a receiver coil $\left(L_{2}\right)$, and two capacitors $\left(C_{1}\right.$ and $\left.C_{2}\right) . L_{1}$ forms a resonance circuit with $C_{1}$, and $L_{2}$ forms a resonance circuit with $C_{2}$. Both resonance circuits are designed to have the same resonance frequency $\omega_{0}=2 \pi \cdot f_{o}=1 / \sqrt{L_{1} C_{1}}=1 / \sqrt{L_{2} C_{2}}$. The transmitter and receiver coils have a mutual inductance, $M_{12}$. The input to the full-bridge inverter is a DC voltage $V_{D C}$. 


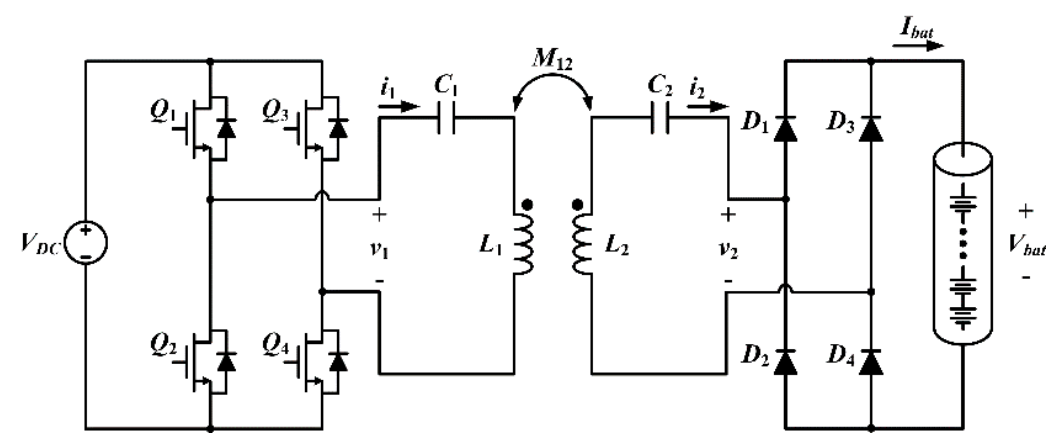

Figure 1. The series and series (S-S) wireless power transfer (WPT) circuit for charging a battery.

To charge a battery, the S-S WPT circuit should be operated in constant current (CC) output mode when the battery voltage $V_{b a t}$ is lower than predetermined limit voltage $V_{b a t, c u t}$, and in constant voltage (CV) mode when $V_{b a t, \text { cut }} \leq V_{\text {bat }}<$ charging voltage limit (CVL) [[9-12]. To support both modes, an additional DC-DC converter can be inserted between the S-S WPT circuit and the battery. However, the additional converter decreases the power transfer efficiency $\eta_{e}$ and the power density $[8,13]$. To solve this problem, the battery can be directly connected to the S-S WPT circuit, as in Figure 1, and several control methods have been introduced [9-13].

The WPT circuit in [9] uses the same S-S WPT circuit (Figure 1) and adopts a pulse frequency modulation (PFM) method to obtain a CV output. In this circuit, the switching frequency range should be selected differently whenever the coupling coefficient is varied, so the range of the frequency limiter cannot be determined easily when the coupling coefficient $k_{12}$ varies widely. Also, wireless communication should be introduced to operate the PFM method. The circuit in [10] improves $\eta_{e}$ by using two intermediate coils that are placed between the transmitter and receiver coils, and uses $f=f_{C C}$ for CC output and $f=f_{C V}$ for $C V$ output, where the frequencies $f_{C C}$ and $f_{C V}$ are determined by the coupling coefficients among the four coils. However, the values of $f_{C C}$ and $f_{C V}$ vary in the manner that any coupling coefficient varies, and no method has been developed to date to measure the coupling coefficients, so accurate determination of $f_{C C}$ and $f_{C V}$ is a difficult task. The circuits in $[11,12]$ use auxiliary switches and capacitors to change the output from CC to CV mode. However, this circuit needs wireless communication to change the operational mode, and additional components also decrease the power density. As mentioned above, most of control methods require wireless communication to know the load conditions and coupling state.

To eliminate the necessity for wireless communication, several load estimation methods have been presented [14-19]. The methods in [14-16] predict the load resistance $R_{L}$ by using the information of the input voltage and current. However, these methods should know the value of the coupling state before estimating the load conditions, so they cannot be used for various coil alignments. The method in [17] adopts an additional capacitor in the S-S WPT circuit; this method operates the circuit in two modes for system identification, and analyzes the reflected impedance. However, the additional capacitor and bidirectional switch increase the circuit cost. The method in [18] measures the input voltage and current, and separates the imaginary part of the input impedance. To estimate the load conditions and coupling state, this method is implemented at one frequency, which is not a resonant frequency, so the impedance of the resonant tank slightly decreases the power transfer efficiency. The method in [19] injects a high frequency energy into the S-S WPT circuit, then detects the response of the circuit to estimate the load conditions. However, this method cannot follow the load conditions after initial energy injection. All of these methods [14-19] can estimate the load conditions well, so they should be able to sense the high-frequency AC input voltage and current. The resonant frequency of the WPT circuit can be up to several hundred kilohertz, so the sampling frequency should be much higher than the resonant frequency; as a result, the analog-to-digital conversion is difficult.

This paper proposes a wireless battery charging circuit along with a load estimation method. This circuit does not need any wireless communication between the transmitter and receiver sides, 
and predicts the load resistance $R_{L}$, output voltage $V_{b a t}$, output current $I_{b a t}$, and mutual inductance $M_{12}$. In addition, because the simple peak current detection circuit is applied at the transmitter coil, the proposed circuit only senses the DC value, and does not need a high sampling frequency. The proposed WPT circuit senses the peak current values of the transmitter coil at $f_{o}$ and auxiliary frequency $f_{a}$, and calculates the load conditions by using these values. Then, the proposed WPT circuit operates in CC and CV modes, depending on the estimated load conditions and phase shift control of the full-bridge inverter. In Section 2, the analysis of the proposed WPT circuit with a load estimation method is given based on the fundamental harmonic approximation (FHA), experimental results are presented in Section 3, possible errors in the proposed estimation method are analyzed in Section 4, and a conclusion is given in Section 5.

\section{Wireless Power Transfer Circuit for Battery Charging}

\subsection{Theoretical Models of the S-S WPT Circuit}

The gate control pulses $Q_{g 1}-Q_{g 4}$ (Figure 2) for the full-bridge inverter have a switching frequency $f=1 / T=\omega /(2 \pi)$. The switching phase of $Q_{g 1}$ and $\bar{Q}_{g 2}$ lags behind that of $Q_{g 3}$ lags behind that of and $\bar{Q}_{g 4}$ by an angle $\phi$, so the bipolar output pulses of the full-bridge inverter ( $v_{1}$, Figure 2$)$ have a dead phase angle $\phi$ between the pulses. The fundamental component of $v_{1}$ is given by

$$
v_{1}(t)=V_{1} \sin (\omega t)=\frac{2 V_{D C}}{\pi}(1+\cos \phi) \sin (\omega t) .
$$

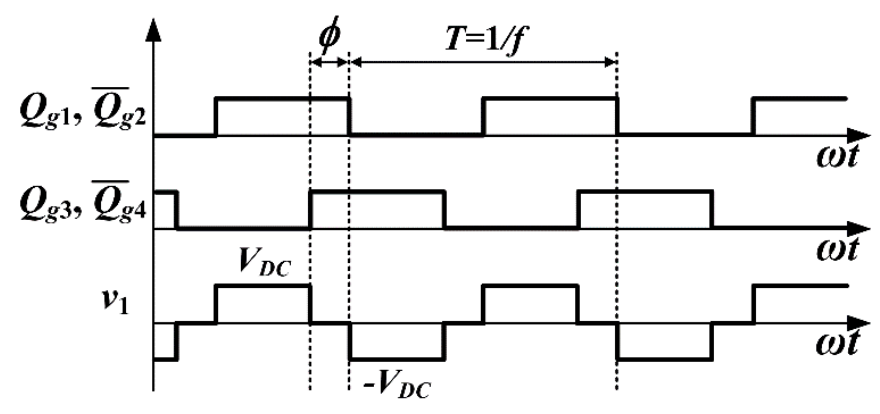

Figure 2. The gate signals and output voltage $v_{1}$ of the full-bridge inverter.

The current $i_{1}(t)$ of the transmitter coil, the current $i_{2}(t)$ of the receiver coil, and the input voltage $v_{2}(t)$ to the rectifier in Figure 1 can be expressed as

$$
\begin{gathered}
i_{1}=I_{1} \sin (\omega t+\theta) \\
v_{2}(t)=V_{2} \sin (\omega t+\theta+\phi)=\frac{4 V_{b a t}}{\pi} \sin (\omega t+\theta+\phi) \\
i_{2}(t)=I_{2} \sin (\omega t+\theta+\phi)=\frac{I_{b a t} \pi}{2} \sin (\omega t+\theta+\phi),
\end{gathered}
$$

where $\theta$ and $\phi$ are phase angles, $V_{b a t}$ is the battery voltage, and $I_{b a t}$ is the averaged charging current of the battery.

The S-S WPT circuit had an equivalent circuit (Figure 3) for the fundamental component, where $R_{i n}, R_{1}$, and $R_{2}$ are the equivalent series resistances (ESRs) of the full-bridge inverter, primary coil, and secondary coil, respectively. Using Equations (3) and (4), the equivalent resistance of the battery $R_{b a t}$ can be modeled with an equivalent resistance $R_{L, e q}$ as:

$$
R_{L, e q}=\frac{8}{\pi^{2}} \cdot R_{b a t}=\frac{8}{\pi^{2}} \cdot \frac{V_{b a t}}{I_{b a t}} .
$$




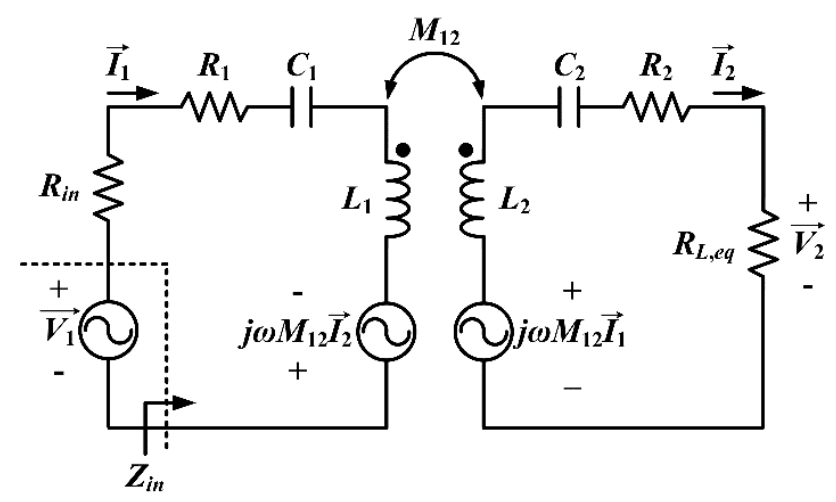

Figure 3. Equivalent circuit for the S-S WPT circuit. Rin, R1, and R2 are equivalent series resistances of the full-bridge inverter, primary coil, and secondary coil, respectively.

Then, the Kirchhoff's voltage law (KVL) gives

$$
\begin{gathered}
\vec{V}_{1}=\left(R_{i n}+Z_{1}\right) \vec{I}_{1}-j \omega M_{12} \vec{I}_{2} \\
j \omega M_{12} \vec{I}_{1}=\left(Z_{2}+R_{L, e q}\right) \vec{I}_{2},
\end{gathered}
$$

where $Z_{1}=R_{1}+j \omega L_{1}+1 /\left(j \omega C_{1}\right)$ and $Z_{2}=R_{2}+j \omega L_{2}+1 /\left(j \omega C_{2}\right)$. Using Equations (6) and (7), the phase of the input impedance $Z_{\text {in }}$ (Figure $4 a$ ), the voltage conversion ratio $T_{v}$ (Figure $4 b$ ), the amplitude of $i_{1}(t)$, the peak current of $i_{1}(\mathrm{t})\left(I_{1}\right)$ (Figure 4c), the amplitude of $i_{2}(t)$, and the peak current of $i_{2}(\mathrm{t})\left(I_{2}\right)$ (Figure $4 \mathrm{~d}$ ) are calculated as

$$
\begin{aligned}
& \vec{Z}_{\text {in }}=\frac{\vec{V}_{1}}{\vec{I}_{1}}=\frac{\left(R_{\text {in }}+Z_{1}\right)\left(Z_{2}+R_{L, e q}\right)+\omega^{2} M_{12}^{2}}{Z_{2}+R_{L, e q}}, \\
& T_{v}=\left|\frac{\vec{V}_{2}}{\vec{V}_{1}}\right|=\left|\frac{R_{L, e q} \vec{I}_{2}}{\vec{V}_{1}}\right|=\left|\frac{j \omega M_{12} R_{L, e q}}{\left(R_{\text {in }}+Z_{1}\right)\left(Z_{2}+R_{L, e q}\right)+\omega^{2} M_{12}^{2}}\right|, \\
& I_{1}=\left|\frac{Z_{2}+R_{L, e q}}{\left(R_{\text {in }}+Z_{1}\right)\left(Z_{2}+R_{L, e q}\right)+\omega^{2} M_{12}^{2}}\right| \cdot V_{1}, \\
& I_{2}=\left|\frac{j \omega M_{12}}{\left(R_{i n}+Z_{1}\right)\left(Z_{2}+R_{L, e q}\right)+\omega^{2} M_{12}^{2}}\right| \cdot V_{1} .
\end{aligned}
$$

\subsection{Load Estimation Method Using the Magnitue of Input Impedance}

The proposed circuit uses the simple peak detection circuit (Figure 5) in [20] to measure the peak current of the transmitter coil $I_{1}$ as a DC value. The peak detection circuit is composed of a current sensor, an amplifier for the peak detection $\left(A_{1}\right)$, an amplifier for the voltage follower $\left(A_{2}\right)$, an input resistance of peak detector $\left(R_{i}\right)$, a feedback loop resistance $\left(R_{f}\right)$, a feedback loop diode $\left(D_{f}\right)$, a rectification diode $\left(D_{o}\right)$, an output capacitor $\left(C_{o}\right)$, and an output resistance $\left(R_{o}\right)$. If the output voltage of the current sensor $\left(V_{s}\right)$ is lower than the voltage of $C_{o}\left(V_{o}\right), D_{f}$ remains on, and $D_{o}$ remains off. In this operating mode, the output voltage of $A_{2}\left(V_{\text {out }}\right)$ is clamped to $V_{o}$, and $C_{o}$ is discharged by $R_{o}$. When $V_{o}$ becomes smaller than $V_{s}, D_{f}$ is turned off and $D_{o}$ is turned on. In this operating mode, $C_{o}$ is charged to the new positive peak of $V_{s}$, so $V_{s}=V_{o}=V_{\text {out }}$. 

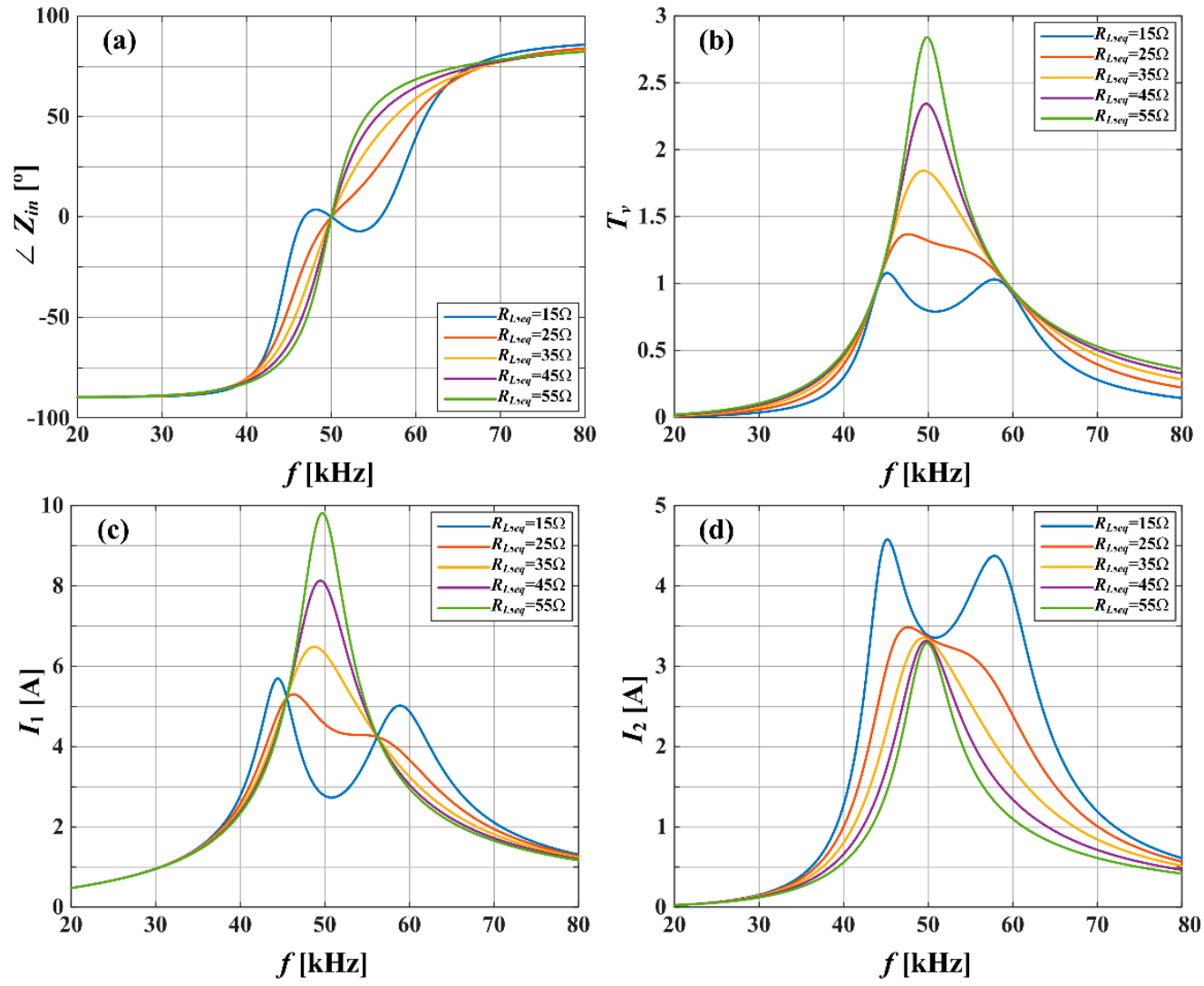

Figure 4. Electrical characteristics of the S-S WPT circuit for $V_{D C}=50 \mathrm{~V}, \phi=0, L_{1}=202.49 \mu \mathrm{H}, L_{2}=$ $202.06 \mu \mathrm{H}, C_{1}=49.97 \mathrm{nF}, C_{2}=50.09 \mathrm{nF}, M_{12}=59.18 \mu \mathrm{H}, R_{\text {in }}=12 \mathrm{~m} \Omega, R_{1}=252 \mathrm{~m} \Omega$, and $R_{2}=248 \mathrm{~m} \Omega$ : (a) phase angle of $Z_{i n} ;(\mathbf{b})$ voltage gain $T_{v} ;(\mathbf{c})$ amplitude of $I_{1}$; and (d) amplitude of $I_{2}$.

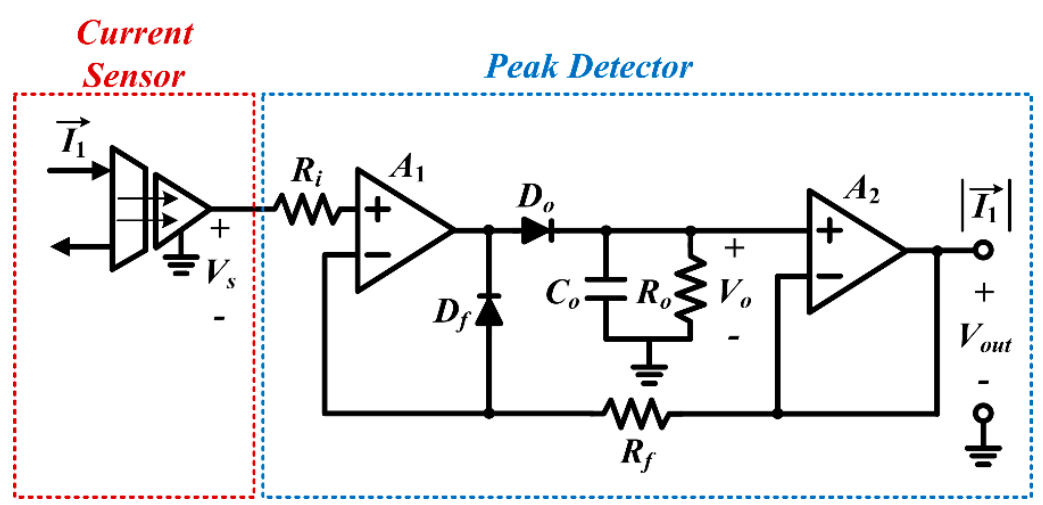

Figure 5. The peak detection circuit to measure the peak current of the transmitter coil.

To estimate the load conditions, the peak detection circuit measures the peak current $I_{1,0}$ at $f=$ $f_{o}$ and $I_{1, a}$ at $f=f_{a}$, respectively, and uses simple mathematical equations for the input impedance. The measurement time of $I_{1, o}$ and $I_{1, a}$ is short, so the load conditions are assumed to remain constant during the estimation process. Also, the system parameters of the transmitter side $\left(V_{D C}, \phi, L_{1}, C_{1}\right.$ and $\left.R_{1}\right)$ and receiver side $\left(L_{2}, C_{2}\right.$ and $\left.R_{2}\right)$ are assumed to be known, and the proposed method predicts $M_{12}$, $R_{L, e q}, I_{b a t}$, and $V_{b a t}$.

At first, the circuit operates at $f=f_{0}$, and the $M_{12}$ can be expressed using detected $I_{1,0}$ and Equation (8) as

$$
M_{12}^{2}=\frac{\left[R_{2}+R_{L, e q}\right] \cdot\left[V_{1, o}-I_{1, o}\left(R_{i n}+R_{1}\right)\right]}{\omega_{o}^{2} \cdot I_{1, o}} .
$$


where $V_{1,0}$ is the peak voltage of the transmitter coil at $f=f_{o}, V_{1,0}=2 V_{D C}(1+\cos \phi) / \pi$ from Equation (1), and the unknown parameters of Equation (12) are $M_{12}$ and $R_{L, e q}$.

Then, the circuit operates at $f=f_{a}$, and the square of the absolute value of input impedance $\left|\vec{Z}_{i n, a}\right|^{2}=V_{1, a}^{2} / I_{1, a}^{2}$ can be expressed using Equation (8) as

$$
\left|\vec{Z}_{i n, a}\right|^{2}=\left(R_{1}+R_{i n}\right)^{2}+\left(\omega_{a} L_{1}-1 / \omega_{a} C_{1}\right)^{2}+\frac{\left.\left.2 \omega_{a}^{2} M_{12}^{2}\right\}\left(R_{1}+R_{i n}\right)\left(R_{2}+R_{L, e q}\right)-\left(\omega_{a} L_{1}-1 / \omega_{a} C_{1}\right)\left(\omega_{a} L_{2}-1 / \omega_{a} C_{2}\right)\right\}+\omega_{a}^{4} M_{12}^{4}}{\left(R_{2}+R_{L, e q}\right)^{2}+\left(\omega_{a} L_{2}-1 / \omega_{a} C_{2}\right)^{2}},
$$

where $V_{1, a}, I_{1, a}$ is the peak voltage and current of transmitter coil at $f=f_{a}, V_{1, a}=2 V_{D C}(1+\cos \phi) / \pi$ from Equation (1). In this equation, the unknown parameters are the same as Equation (12).

If Equation (12) is applied to Equation (13), the $R_{L, e q}$ can be arranged as $\alpha R_{L, e q}^{2}+\beta R_{L, e q}+\gamma=0$, where $\alpha, \beta$ and $\gamma$ are as follows:

$$
\begin{aligned}
& \alpha=\omega_{0}^{4} I_{1, o}^{2}\left|\vec{Z}_{i n, a}\right|^{2}-\omega_{0}^{4} I_{1, o}^{2}\left\{\left(R_{1}+R_{i n}\right)^{2}+\left(\omega_{a} L_{1}-1 / \omega_{a} C_{1}\right)^{2}\right\}-2 \omega_{a}^{2} \omega_{0}^{2} I_{1, o}\left\{R_{1}+R_{i n}\right\} \cdot\left\{V_{1, o}-I_{1, o}\left(R_{i n}+R_{1}\right)\right\} \\
& -\omega_{a}^{4}\left\{V_{1, o}-I_{1, o}\left(R_{i n}+R_{1}\right)\right\}^{2} \\
& \beta=2 R_{2} \omega_{0}^{4} I_{1, o}^{2}\left|Z_{i n, a}\right|^{2}-2 R_{2} \omega_{0}^{4} I_{1, o}^{2}\left\{\left(R_{1}+R_{i n}\right)^{2}+\left(\omega_{a} L_{1}-1 / \omega_{a} C_{1}\right)^{2}\right\} \\
& -2 \omega_{a}^{2} \omega_{0}^{2} I_{1, o}\left\{2 R_{2}\left(R_{1}+R_{i n}\right)-\left(\omega_{a} L_{1}-1 / \omega_{a} C_{1}\right)\left(\omega_{a} L_{2}-1 / \omega_{a} C_{2}\right)\right\} \cdot\left\{V_{1, o}-I_{1, o}\left(R_{i n}+R_{1}\right)\right\}-2 R_{2} \omega_{a}^{4}\left\{V_{1, o}-I_{1, o}\left(R_{i n}+R_{1}\right)\right\}^{2} \\
& \gamma=\omega_{0}^{4} I_{1,0}^{2}\left|Z_{i n, a}\right|^{2}\left\{R_{2}^{2}+\left(\omega_{a} L_{2}-1 / \omega_{a} C_{2}\right)^{2}\right\}-\omega_{0}^{4} I_{1, o}^{2}\left\{\left(R_{1}+R_{\text {in }}\right)^{2}+\left(\omega_{a} L_{1}-1 / \omega_{a} C_{1}\right)^{2}\right\} \cdot\left\{R_{2}^{2}+\left(\omega_{a} L_{2}-1 / \omega_{a} C_{2}\right)^{2}\right\} \\
& -\omega_{a}^{4} R_{2}^{2}\left\{V_{1, o}-I_{1, o}\left(R_{i n}+R_{1}\right)\right\}^{2}-2 \omega_{a}^{2} \omega_{0}^{2} I_{1, o}\left\{R_{2}^{2}\left(R_{1}+R_{i n}\right)-R_{2}\left(\omega_{a} L_{1}-1 / \omega_{a} C_{1}\right)\left(\omega_{a} L_{2}-1 / \omega_{a} C_{2}\right)\right\} \cdot\left\{V_{1, o}-I_{1, o}\left(R_{\text {in }}+R_{1}\right)\right\}
\end{aligned}
$$

This equation has two solutions for $R_{L, e q}$, and the smaller one is a reasonable value according to the calculation result, so estimated load resistance $R_{L, e q, e s t}$ and estimated equivalent resistance of battery $R_{\text {bat,est }}$ can be estimated as

$$
R_{L, e q, e s t}=\frac{-\beta-\sqrt{\beta^{2}-4 \alpha \cdot \gamma}}{2 \alpha}=\frac{8}{\pi^{2}} \cdot R_{\text {bat }, e s t} .
$$

Then, the estimated mutual inductance $M_{12, \text { est }}$ can also be derived by applying Equation (17) to Equation (12) as:

$$
M_{12, e s t}=\sqrt{\frac{\left[2 \alpha \cdot R_{2}-\beta-\sqrt{\beta^{2}-4 \alpha \cdot \gamma}\right] \cdot\left[V_{1, o}-I_{1, o}\left(R_{\text {in }}+R_{1}\right)\right]}{2 \alpha \cdot \omega_{o}^{2} \cdot I_{1, o}}} .
$$

Other important estimated load parameters $I_{\text {bat,est }}$ and $V_{\text {bat,est }}$ at $f=f_{0}$ can be expressed using Equations (1)-(7), (17), and (18) as

$$
\begin{gathered}
I_{b a t, e s t}=\frac{2 I_{1, o}}{\pi} \cdot \frac{\omega_{0} M_{12, e s t}}{R_{2}+R_{L, e q, e s t}} \\
V_{b a t, e s t}=\frac{\pi^{2}}{8} \cdot I_{b a t, e s t} \cdot R_{L, e q, e s t} .
\end{gathered}
$$

Finally, the proposed method can predict $R_{L, e q}, M_{12}, I_{b a t}$, and $V_{b a t}$, and does not need a high sampling frequency to measure AC voltage and current, similar to previous studies [14-19].

\subsection{Control Method of the S-S WPT Circuit for Battery Charging}

The battery should be charged in CC mode when $V_{b a t} \leq V_{b a t, c u t}$, and in CV mode when $V_{b a t}>$ $V_{b a t, c u t}$. In CV mode, $I_{b a t}$ decreases as $V_{b a t}$ increases, until $I_{b a t}$ reaches the end charging current $I_{\text {end }}$ at which the charging operation stops [9-12]. 
$T_{v}$ and $I_{2}$ in Equations (9) and (11) depend on $R_{L, e q}$, which varies as the charge state of battery varies. When all ESRs are negligibly small, Equation (11) gives $I_{2}$ at $\omega=\omega_{0}$ as

$$
I_{2}=\frac{\omega_{o} M_{12} V_{1}}{\left(R_{\text {in }}+R_{1}\right)\left(R_{2}+R_{L, e q}\right)+\omega_{o}^{2} M_{12}^{2}} \approx \frac{V_{1}}{\omega_{0} M_{12}}
$$

because $Z_{1}=R_{1}$ and $Z_{2}=R_{2}$ when $\omega=\omega_{0}$. This equation indicates that the WPT circuit can be operated in CC mode if all ESRs are ignored and $\omega=\omega_{0}$. However, ESRs affect the capability of CC regulation (Figure 4d), so a separate control method should be introduced to attain CC mode; the proposed WPT circuit applies phase shift control of the full-bridge inverter at $f=f_{0}$, and the $\phi$ to maintain the CC output is compensated by using the proportional integral (PI) controller, which can be calculated as

$$
\phi=\cos ^{-1}\left\{\frac{\pi^{2} \cdot\left(I_{r e f} / 2\right) \cdot\left[\left(R_{\text {in }}+R_{1}\right)\left(R_{2}+R_{L, e q, e s t}\right)+\omega_{o}^{2} M_{12, e s t}^{2}\right]}{2 \omega_{0} M_{12, e s t} V_{D C}}-1\right\},
$$

where $I_{r e f}$ is the predetermined charging current reference. If ESRs are very small in CC mode, the influence of $R_{L, e q}$ in $\phi$ will also be very small.

To operate the WPT circuit in CV mode, $T_{v}$ should not depend on $R_{L, e q}$. If all ESRs are negligible, Equation (9) can be approximated as

$$
T_{v} \approx\left|\left[j \omega M_{12}\right] /\left[\left(j \omega L_{1}+1 / j \omega C_{1}\right)+\kappa / R_{L, e q}\right]\right|,
$$

where $\kappa=\omega^{2}\left(M_{12}^{2}-L_{1} L_{2}\right)-1 /\left(\omega^{2} C_{1} C_{2}\right)+L_{1} / C_{2}+L_{2} / C_{1}$. After setting $\kappa=0$, the frequencies $f_{C V 1}$ and $f_{C V 2}$ for $C V$ operation are obtained as $f_{C V 1}=2 \pi \cdot f_{0} / \sqrt{1+k_{12}}$ and $f_{C V 2}=2 \pi \cdot f_{0} / \sqrt{1-k_{12}}$, and $T_{v}$ at $f=f_{C V 1}$ or $f=f_{C V 2}$ is calculated using Equation (23) and $M_{12}=k_{12} \sqrt{L_{1} L_{2}}$ as $T_{v}=\sqrt{L_{2} / L_{1}}$. However, ESRs in CV mode are also difficult to ignore, and if $f_{C V 1}$ and $f_{C V 2}$ deviate too much from $f_{o}$, the system efficiency also drastically decreases [14]. Therefore, the proposed WPT circuit still operates at $f=f_{0}$ in $\mathrm{CV}$ mode, and the $\phi$ to maintain the CV output is compensated by using the PI controller, which can be calculated as

$$
\phi=\cos ^{-1}\left\{\frac{4 \mathrm{CVL} \cdot\left[\left(R_{\text {in }}+R_{1}\right)\left(R_{2}+R_{L, e q, e s t}\right)+\omega_{o}^{2} M_{12, e s t}^{2}\right]}{2 \omega_{0} M_{12, e s t} V_{D C} R_{L, e q, e s t}}-1\right\} .
$$

The influence of $R_{L, e q}$ in CV mode cannot be ignored, even if ESRs are very small. Thus, $\phi$ will increase as $R_{L, e q}$ increases.

Finally, the proposed S-S WPT circuit applies the control algorithm (Figure 6) for battery charging, and it consists of the following procedures:

(1) Modulate the WPT circuit at $f=f_{o}$ and $f_{a}$; sense the $I_{1, o}$ and $I_{1, a}$, respectively.

(2) Using the $I_{1, o}$ and $I_{1, a}$, estimate $R_{\text {bat }, \text { est }}[1]=V_{\text {bat, est }}[1] / I_{\text {bat,est }}[1]$ and $M_{12, e s t}$.

(3) If $V_{\text {bat, est }}[1]<C V L$, begin the control procedure. Otherwise, turn off the S-S WPT circuit.

(4) Set $f=f_{o}$ to operate the WPT circuit in the CC mode.

(5) Using the PI controller, adjust $\phi[n]$ such that $I_{\text {bat, est }}$ equals to $I_{\text {ref. }}$.

(6) Estimate the $R_{b a t, e s t}[n]=V_{b a t, e s t}[n] / I_{\text {bat,est }}[n]$ by using $I_{1,0}[n]$ and (12); $R_{b a t, e s t}[n]$ is continuously updated to follow the charging profile of battery.

(7) Repeat (5)-(6) until $V_{\text {bat }, e s t}[n]=$ CVL.

(8) Change the operation of WPT circuit from the CC to CV mode, and maintain $f=f_{0}$.

(9) Using the PI controller, adjust $\phi[n]$ such that $V_{\text {bat }, e s t}=$ CVL.

(10) Repeat procedure 6 until $I_{\text {bat }, \text { est }}[\mathrm{n}]=I_{\text {end }}$.

(11) Turn off the S-S WPT circuit. 


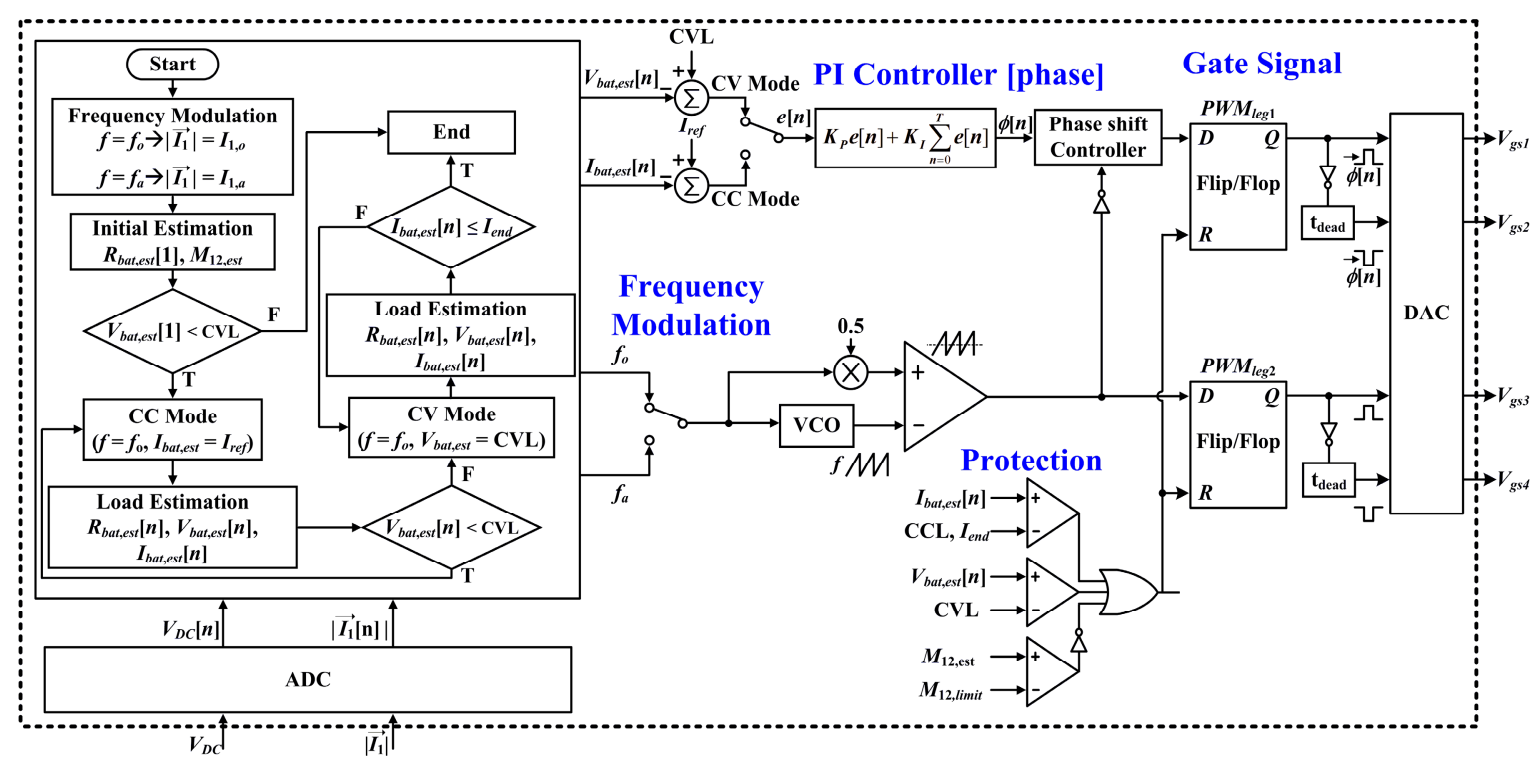

Figure 6. A block diagram of the digital controller for the S-S wireless battery charging circuit.

The controller has a protection function for charging current limit (CCL), CVL, and coil alignment of the WPT circuit. When $M_{12, e s t}<M_{12 \text {,limit }}$, the controller terminates the battery-charging operation, because the alignment of the coils is inappropriate for battery charging.

\section{Experimental Results}

The experimental S-S WPT circuit for battery charging (Figure 7a,b) was built and tested to prove the proposed control method. Two identical coils had an inner diameter of $100 \mathrm{~mm}$ and outer diameter of $200 \mathrm{~mm} ; L_{1}=202.49 \mu \mathrm{H}, L_{2}=202.06 \mu \mathrm{H}$, and $C_{1}=C_{2}=50 \mathrm{nF}$ were chosen for $f_{o}=50 \mathrm{kHz}$. The input voltage $V_{D C}$ was $50 \mathrm{~V}$, and the sampling frequency to sense the output value of the peak detector was set as $50 \mathrm{kHz}$, which was simply synchronized to the $f_{o}$. The values of circuit parameters are given in Table 1.

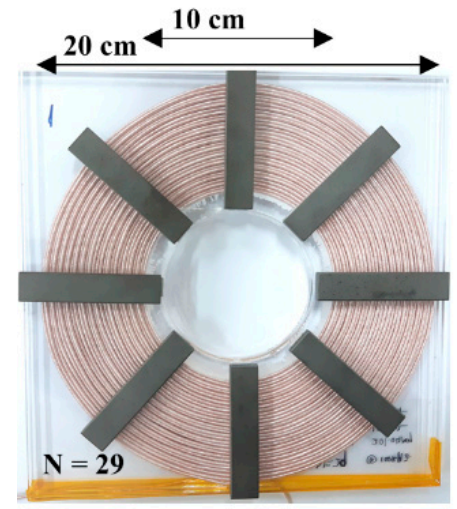

(a)

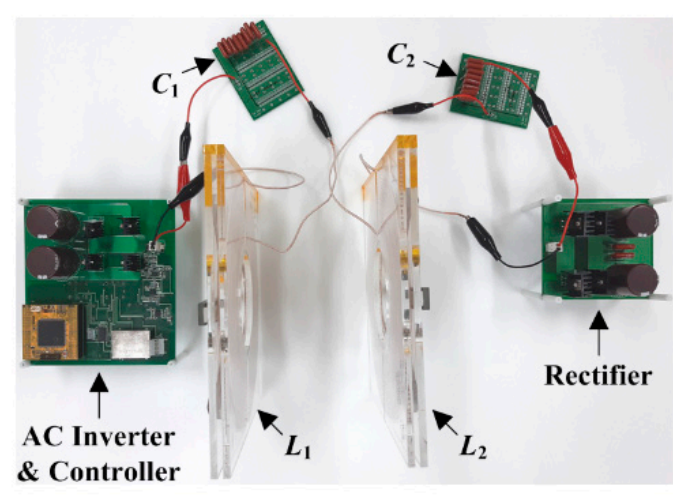

(b)

Figure 7. Photograph of the (a) transmitter coil and (b) experimental S-S WPT circuit. 
Table 1. Circuit parameters for the experimental circuit.

\begin{tabular}{cc}
\hline Component & Value (Model) \\
\hline$L_{1}$ & $202.49 \mu \mathrm{H}$ \\
$L_{2}$ & $202.06 \mu \mathrm{H}$ \\
$C_{1}$ & $49.97 \mathrm{nF}$ \\
$C_{2}$ & $50.09 \mathrm{nF}$ \\
$R_{\text {in }}$ & $12 \mathrm{~m} \Omega$ \\
$R_{1}$ & $252 \mathrm{~m} \Omega$ \\
$R_{2}$ & $248 \mathrm{~m} \Omega$ \\
$Q_{1}-Q_{4}$ & FDP0715N15A \\
$D_{1}-D_{4}$ & $30 \mathrm{ETH} 06$ \\
Controller & TMS320F28335 \\
\hline
\end{tabular}

First, the load estimation was performed using the method in Section 2.2. $R_{b a t}$ and $M_{12}$ between the transmitter and receiver coils were measured and estimated using electrical load (DL1000H; NF, Co., Ltd.) and a inductance, capacitance and resistance (LCR) meter. The coil alignment was modulated on either the separation $h$ in the axial direction of the coil or the misalignment $v$ in the radial direction (Figure 8). At $h=6 \mathrm{~cm}$ and $v=0 \mathrm{~cm}$, the WPT circuit was operated at $f_{o}=50 \mathrm{kHz}$ and $f_{a}=55 \mathrm{kHz}$ to estimate the load condition, and $R_{b a t}=20.11 \Omega$ and $M_{12}=48.81 \mu \mathrm{H}$ at $\phi=0$. The measured $I_{1, o}=4.21 \mathrm{~A}$ (Figure $9 \mathrm{a}$ ) and $I_{1, a}=5.08 \mathrm{~A}$ (Figure $9 \mathrm{~b}$ ), and the estimated load conditions were $R_{\text {bat, }, e s t}=20.49 \Omega$ and $M_{12, e s t}=49.30 \mu \mathrm{H}$ by using Equations (17) and (18). The errors of estimation results were $-1.88 \%$ and $-1.86 \%$, respectively; other estimation results were obtained while varying $h, v$, and $R_{b a t}$ (Tables 2 and 3). Here, $h$ was varied in the range of $5-7 \mathrm{~cm}$ at $v=0 \mathrm{~cm}, v$ was varied in the range of $0-6 \mathrm{~cm}$ at $h=0$ $\mathrm{cm}$, and $R_{b a t}$ was varied in the range of 15.06-25.17 $\Omega$. As a result, the proposed method estimated the $R_{b a t}$ and $M_{12}$ within absolute errors at $<3.87 \%$ and $<3.38 \%$, respectively. These experimental results demonstrate the usefulness of the proposed load estimation method. The errors of estimation were caused by inductance variation according to the coil alignment conditions and measurement error at $f_{o}$ and $f_{a}$. A detailed error analysis is given in the next section.

The current and voltage regulation for the battery charging were implemented using the controller proposed in Section 2.3. An electrical load was used to emulate the battery pack, which was assumed to have $30 \mathrm{~V} \leq V_{b a t} \leq 48 \mathrm{~V}$ (corresponding to a pack of 12 serially connected Li-ion battery cells). The $R_{b a t}$ of the battery pack was $15 \Omega \leq R_{b a t} \leq 24 \Omega$ for CC charging at $I_{r e f}=2 \mathrm{~A}$ and $24 \Omega \leq R_{b a t} \leq 240 \Omega$ for $\mathrm{CV}$ charging at $\mathrm{CVL}=48 \mathrm{~V}$ and $I_{\text {end }}=200 \mathrm{~mA}$. The transmitter and receiver coils were located at $h$ $=5 \mathrm{~cm}$ and $v=0 \mathrm{~cm}$. In procedures 1 and 2, the controller of the WPT circuit used $f_{o}=50 \mathrm{kHz}$ and $f_{a}=$ $55 \mathrm{kHz} ; R_{\text {bat }, \text { est }}(1)=15.51 \Omega$ at $R_{\text {bat }}=15.01 \Omega(-3.33 \%$ error $)$ and $M_{12, e s t}=59.78 \mu \mathrm{H}$ at $M_{12}=59.18 \mu \mathrm{H}$ $\left(-1.01 \%\right.$ error). Because $V_{\text {bat }, \text { st }}(1)=31.02 \mathrm{~V}<\mathrm{CVL}$ in procedure 3 , the controller began the charging control procedures in steps 4-11.

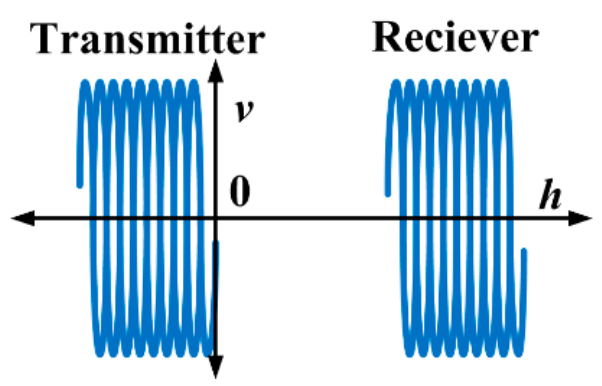

Figure 8. Alignment schematic of the two coils from top view. 


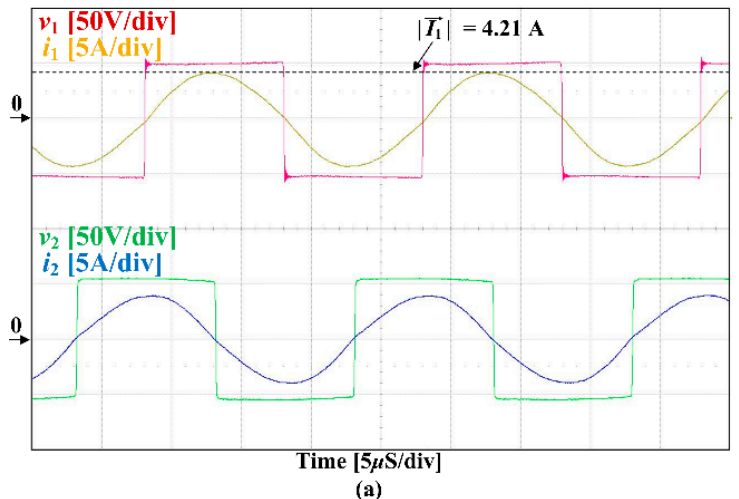

(a)

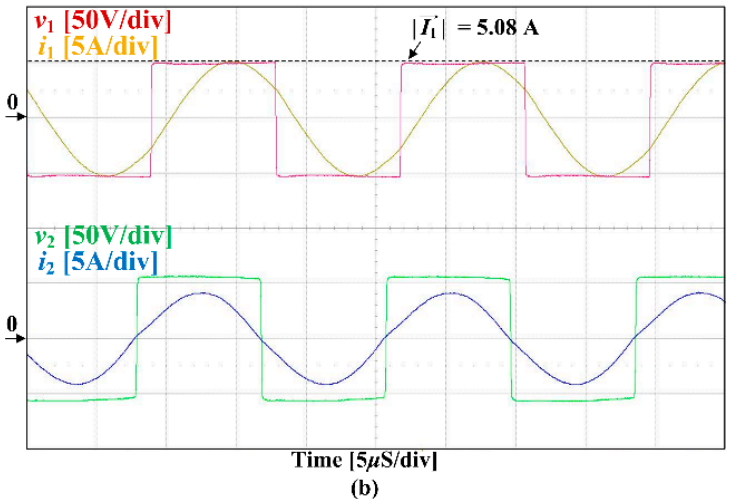

(b)

Figure 9. Operation wave forms of the proposed WPT circuit: (a) $v_{1}, i_{1}, v_{2}$, and $i_{2}$ at $f_{0}=50 \mathrm{kHz}$; (b) $v_{1}$, $i_{1}, v_{2}$, and $i_{2}$ at $f_{a}=55 \mathrm{kHz}$.

Table 2. Estimation results for $R_{b a t}$.

\begin{tabular}{|c|c|c|c|c|c|c|}
\hline$h, v(\mathrm{~cm})$ & $R_{\text {bat }}(\Omega)$ & $\begin{array}{l}R_{\text {bat,est }}(\Omega) \\
(\text { Error }(\%))\end{array}$ & $R_{b a t}(\Omega)$ & $\begin{array}{l}R_{\text {bat,est }}(\Omega) \\
(\text { Error }(\%))\end{array}$ & $R_{b a t}(\Omega)$ & $\begin{array}{l}R_{\text {bat, est }}(\Omega) \\
(\text { Error }(\%))\end{array}$ \\
\hline 5,0 & \multirow{6}{*}{15.06} & $15.20(-0.92)$ & \multirow{6}{*}{20.11} & $19.61(2.48)$ & \multirow{6}{*}{25.17} & $24.22(3.77)$ \\
\hline 6,0 & & $15.60(-3.58)$ & & $20.49(-3.58)$ & & $25.31(-0.55)$ \\
\hline 7,0 & & $15.54(-3.18)$ & & $20.54(-2.08)$ & & $25.35(-0.71)$ \\
\hline 5,2 & & $15.46(-2.66)$ & & $19.72(1.90)$ & & $24.19(3.87)$ \\
\hline 5,4 & & $15.45(-2.58)$ & & $20.37(-1.29)$ & & $25.11(0.23)$ \\
\hline 5,6 & & $15.60(-3.58)$ & & $20.27(-0.79)$ & & $24.84(1.31)$ \\
\hline
\end{tabular}

Table 3. Estimation results for $M_{12}$.

\begin{tabular}{|c|c|c|c|c|}
\hline$h, v(\mathrm{~cm})$ & $M_{12}(\mu \mathrm{H})$ & $\begin{array}{c}M_{12, e s t}(\mu \mathrm{H}) \\
@ 15.06 \Omega \\
(\text { Error }(\%))\end{array}$ & $\begin{array}{c}M_{12, \text { est }}(\mu \mathrm{H}) \\
@ 20.11 \Omega \\
(\text { Error }(\%))\end{array}$ & $\begin{array}{c}M_{12, e s t}(\mu \mathrm{H}) \\
@ 25.17 \Omega \\
(\text { Error }(\%))\end{array}$ \\
\hline 5,0 & 59.18 & $58.41(1.30)$ & $58.7(0.81)$ & $59.03(0.26)$ \\
\hline 6,0 & 48.81 & $49.27(-0.92)$ & $49.73(-1.86)$ & $49.76(-1.92)$ \\
\hline 7,0 & 40.76 & $41.12(-3.18)$ & $41.59(-2.08)$ & $41.62(-2.08)$ \\
\hline 5,2 & 57.28 & $55.37(3.38)$ & $55.73(2.71)$ & $55.85(2.50)$ \\
\hline 5,4 & 49.54 & $49.28(0.53)$ & $49.68(-0.26)$ & $49.79(-0.49)$ \\
\hline 5,6 & 38.66 & $39.55(-2.28)$ & $39.49(-2.12)$ & $39.44(-1.99)$ \\
\hline
\end{tabular}

In the CC mode of procedures 4-7, the waveform (Figure 10) shows that $v_{1}$ and $i_{1}$ had the same phase because the S-S WPT circuit operated at $f=f_{o}$, and that $\phi$ was compensated to regulate $I_{b a t, e s t}$ $=I_{r e f}$. When the circuit operated at $R_{b a t}=15.01 \Omega$ (Figure $\left.10 \mathrm{a}\right), I_{b a t}=2.07 \mathrm{~A}(-3.5 \%$ error $)$ and $V_{b a t}=$ $31.21 \mathrm{~V}$. In this CC mode, $V_{b a t}$ increased as $R_{b a t}$ increased because $I_{b a t, e s t}$ tracked the predetermined $I_{r e f}$ $=2 \mathrm{~A}$. The waveform of Figure $10 \mathrm{~b}$ shows that $V_{\text {bat }}$ increased to $46.55 \mathrm{~V}$ at $R_{\text {bat }}=22.47 \Omega$, while $I_{\text {bat }}$ $=2.07 \mathrm{~A}\left(-3.5 \%\right.$ error). When procedure 5 was used in the CC mode, the range of regulated $I_{b a t}$ was 2.074-2.079 A; the tracking absolute error was $<3.95 \%$ (Figure 12). The power transfer efficiency of the CC mode gradually increased as $R_{b a t}$ increased, and the range of it was 88.81-92.05\% (Figure 13). After $V_{\text {bat }, e s t}$ reached $\mathrm{CVL}=48 \mathrm{~V}$, the charging mode was changed to $\mathrm{CV}$ mode in the procedures 8-11. 


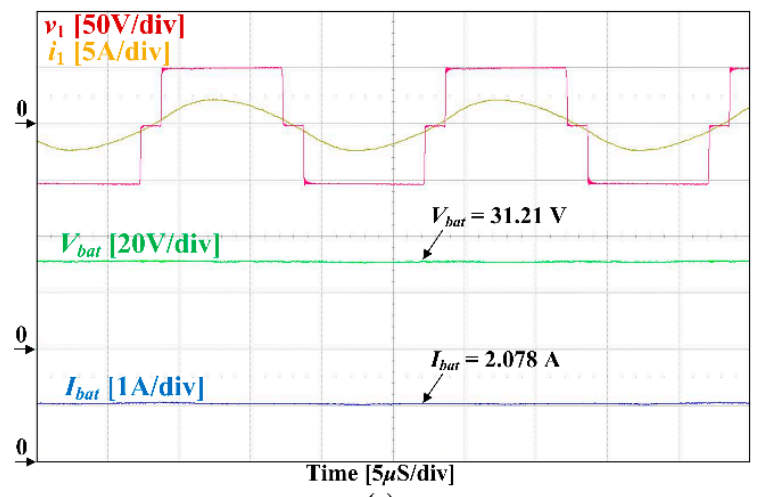

(a)

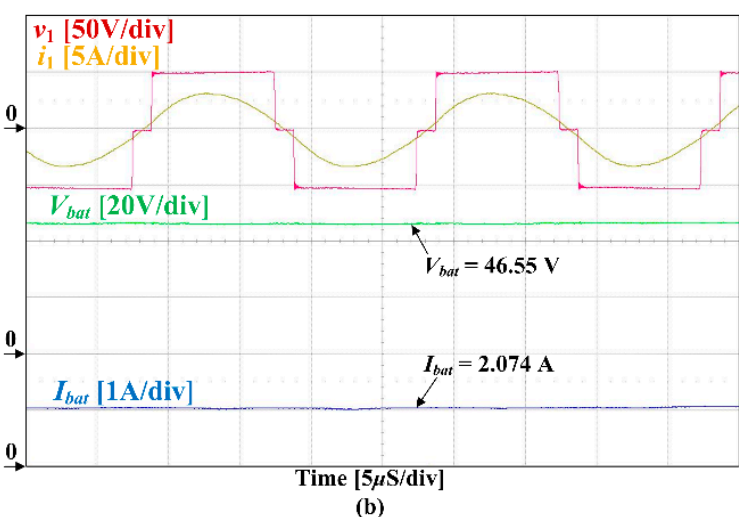

(b)

Figure 10. Operation wave forms of the proposed WPT circuit: $v_{1}, i_{1}, V_{b a t}$, and $I_{b a t}$ in the CC mode (a) at $R_{b a t}=15.01 \Omega$ and (b) at $R_{b a t}=22.47 \Omega$.

The waveform of CV mode (Figure 11) also shows that $v_{1}$ and $i_{1}$ had the same phase because the S-S WPT circuit operated at $f=f_{o}$, and that $\phi$ was compensated to regulate $V_{b a t, e s t}=\mathrm{CVL}$. When the circuit operated at $R_{b a t}=54.10 \Omega$ (Figure $\left.11 \mathrm{a}\right), V_{b a t}=47.24 \mathrm{~V}\left(1.58 \%\right.$ error) and $I_{b a t}=0.88 \mathrm{~A}$. In this CV mode, as $R_{b a t}$ increased, $T_{v}$ increased (Figure $4 \mathrm{~b}$ ); $\phi$ should be increased to maintain $V_{b a t}$. Thus, $I_{b a t}$ gradually decreased until $I_{b a t, e s t}=I_{\text {end }}$. The waveform of Figure $11 \mathrm{~b}$ shows that $I_{b a t}$ decreased to $0.2 \mathrm{~A}$ at $R_{b a t}=244 \Omega$, while $V_{b a t}=47.92 \mathrm{~V}(0.16 \%$ error $)$. When procedure 9 was used, the range of regulated $V_{b a t}$ was $47.09-47.92 \mathrm{~V}$; the tracking absolute error was $<1.89 \%$ (Figure 12). The power transfer efficiency of the CV mode gradually decreased as $R_{b a t}$ increased, and the range was 74.77-92.49\% (Figure 13).

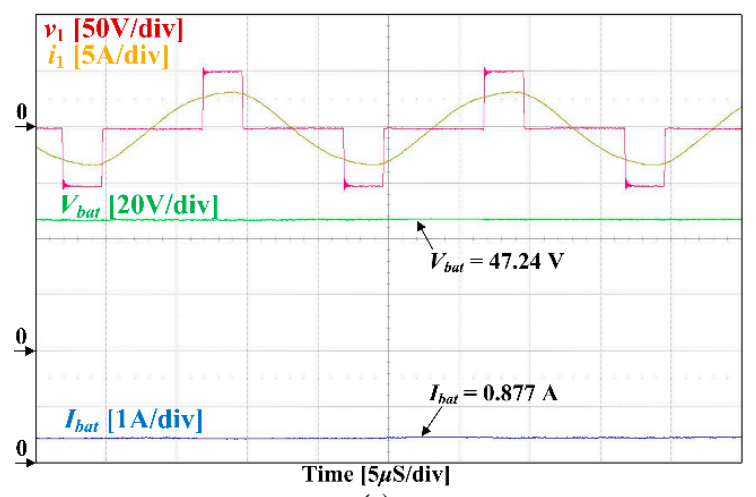

(a)

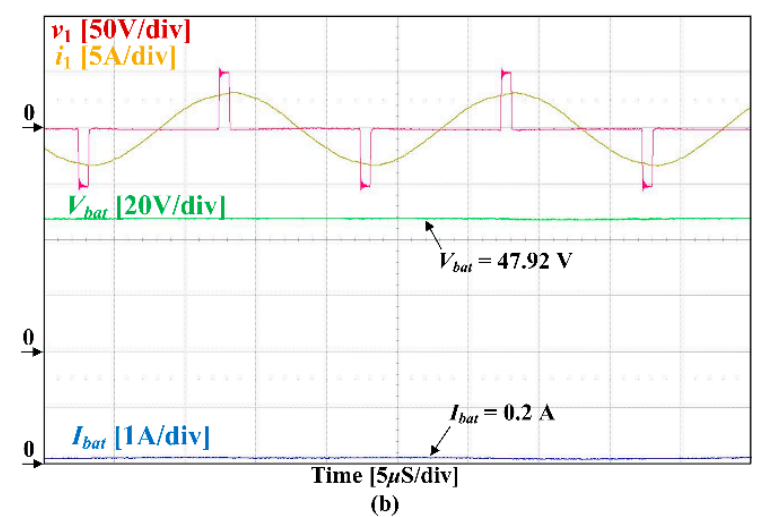

(b)

Figure 11. Operation wave forms of the proposed WPT circuit: v1, i1, Vbat, and Ibat in the CV mode (a) at $\mathrm{Rbat}=54.10 \Omega$ and $(\mathbf{b})$ at $\mathrm{Rbat}=244 \Omega$.

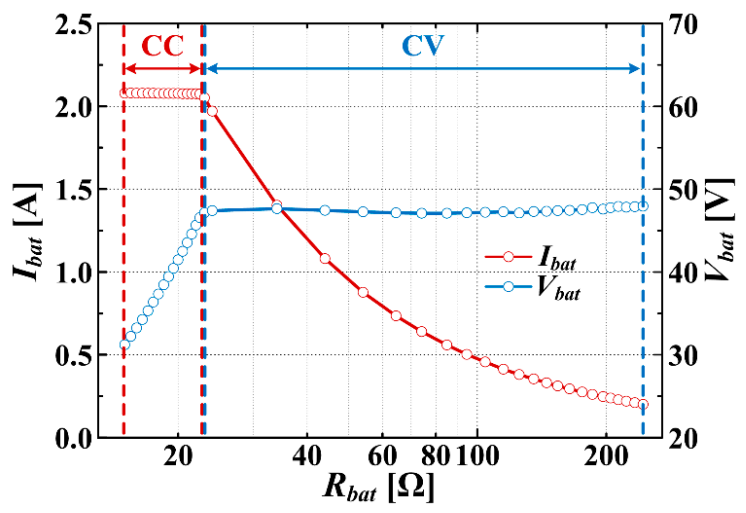

Figure 12. Measurement of regulated $I_{b a t}$ and $V_{b a t}$ in constant current (CC) and constant voltage (CV) modes. 


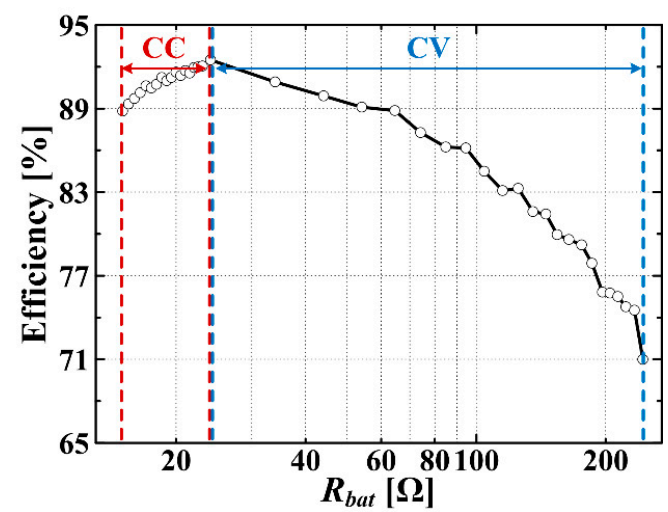

Figure 13. Power transfer efficiency of the proposed WPT circuit in CC and CV modes.

These results show that the proposed load estimation method is suitable for use in battery charging, and that the adjustment of $\phi$ was crucial to have $I_{b a t}$ follow $I_{\text {ref }}$ in CC charging mode and to have $V_{b a t}$ follow CVL in CV charging mode.

\section{Error Analysis}

In the proposed estimation method, the errors of estimation results can be generated using the deviated inductance $\left(L_{d e v}\right)$ according to the coil alignment and measurement error of input impedance at $f_{o}$ and $f_{a}$. Therefore, these errors of the proposed method were analyzed by using MATLAB (R2015a, MathWorks, Massachusetts, USA) in this section.

In this section, the errors of estimation results due to the $L_{d e v}$ (Figure 14a,b) were calculated as

$$
\begin{aligned}
& \operatorname{Error}\left(R_{b a t, e s t, d e v}\right)=\left[\left(R_{b a t}-R_{b a t, e s t}\left(L_{\text {dev }}\right)\right) / R_{b a t}\right] \times 100, \\
& \operatorname{Error}\left(M_{12, e s t, d e v}\right)=\left[\left(M_{12}-M_{12, e s t}\left(L_{d e v}\right)\right) / M_{12}\right] \times 100,
\end{aligned}
$$

where $R_{b a t, e s t}\left(L_{d e v}\right)$ and $M_{12, e s t}\left(L_{d e v}\right)$ are estimated $R_{b a t}$ and $M_{12}$ in the $L_{d e v}$. The measurement errors of input impedance (Figure 14c-f) were calculated as

$$
\begin{aligned}
& \text { Error }\left|\vec{Z}_{i n, a}\right|=\left[\left(\left|\vec{Z}_{i n, a}\right|-\left|\vec{Z}_{\text {in,a,measure }}\right|\right) /\left|\vec{Z}_{i n, a}\right|\right] \times 100, \\
& \text { Error }\left|\vec{Z}_{i n, o}\right|=\left[\left(\left|\vec{Z}_{i n, o}\right|-\left|\vec{Z}_{\text {in,o,measure }}\right|\right) /\left|\vec{Z}_{i n, o}\right|\right] \times 100,
\end{aligned}
$$

where $\left|\vec{Z}_{\text {in,a,measure }}\right|$ and $\left|\vec{Z}_{\text {in,o,measure }}\right|$ are measured values of $\left|\vec{Z}_{\text {in, } a}\right|$ and $\left|\vec{Z}_{i n, o}\right|$ at $f=f_{a}$ and $f=f_{o}$ by using a peak detection circuit in Figure 5. Then, the errors of estimation results due to the Error $\left|\vec{Z}_{\text {in,a }}\right|$ and Error $\left|\vec{Z}_{i n, o}\right|$ (Figure 14c-f) were calculated as

$$
\begin{aligned}
& \operatorname{Error}\left(R_{\text {bat }, e s t, f a}\right)=\left[\left(R_{\text {bat }}-R_{\text {bat }, \text { est }}\left(\left|\vec{Z}_{\text {in,a,measure }}\right|\right)\right) / R_{\text {bat }}\right] \times 100, \\
& \operatorname{Error}\left(M_{12, e s t, f a}\right)=\left[\left(M_{12}-M_{12, e s t}\left(\left|\vec{Z}_{\text {in,a,measure }}\right|\right)\right) / M_{12}\right] \times 100, \\
& \operatorname{Error}\left(R_{\text {bat,est }, f o}\right)=\left[\left(R_{\text {bat }}-R_{\text {bat }, \text { est }}\left(\left|\vec{Z}_{\text {in,o,measure }}\right|\right)\right) / R_{\text {bat }}\right] \times 100, \\
& \operatorname{Error}\left(M_{12, e s t, f o}\right)=\left[\left(M_{12}-M_{12, e s t}\left(\left|\vec{Z}_{\text {in,o,measure }}\right|\right)\right) / M_{12}\right] \times 100,
\end{aligned}
$$


where $R_{\text {bat }, e s t}\left(\left|\vec{Z}_{\text {in,a,measure }}\right|\right)$ and $M_{12, e s t}\left(\left|\vec{Z}_{\text {in,a,measure }}\right|\right)$ are $R_{\text {bat,est }}$ and $M_{12, \text { est }}$ in the Error $\left|\vec{Z}_{\text {in,a }}\right|$, and $R_{\text {bat }, \text { est }}\left(\mid \vec{Z}_{\text {in,o,measure }}\right)$ and $M_{12, e s t}\left(\left|\vec{Z}_{\text {in,o,measure }}\right|\right)$ are $R_{\text {bat }, \text { st }}$ and $M_{12, e s t}$ in the Error $\left|\vec{Z}_{\text {in,o }}\right|$.

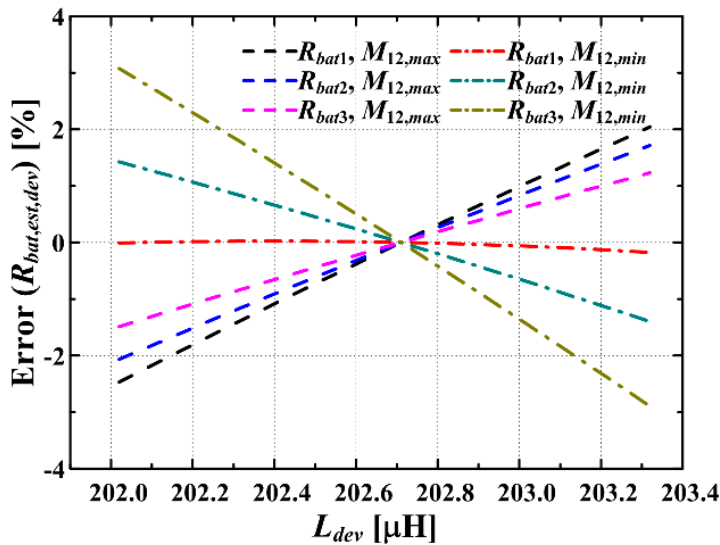

(a)

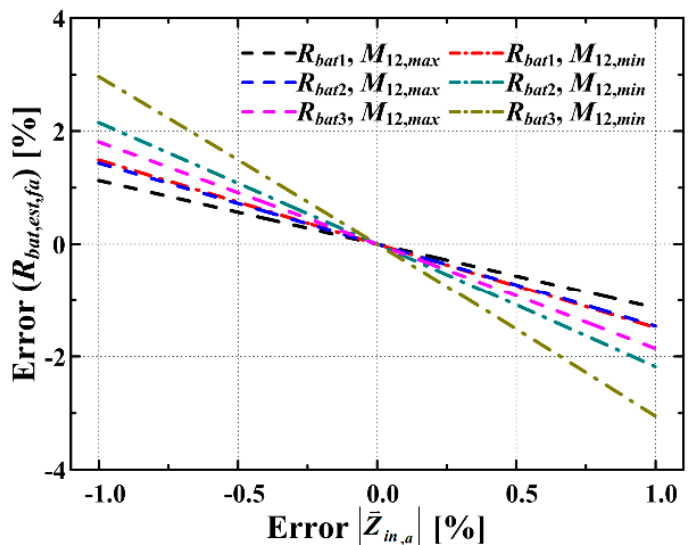

(c)

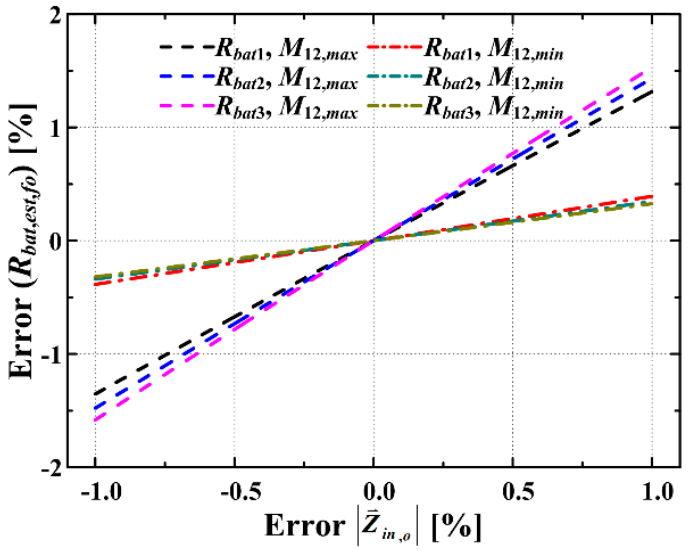

(e)

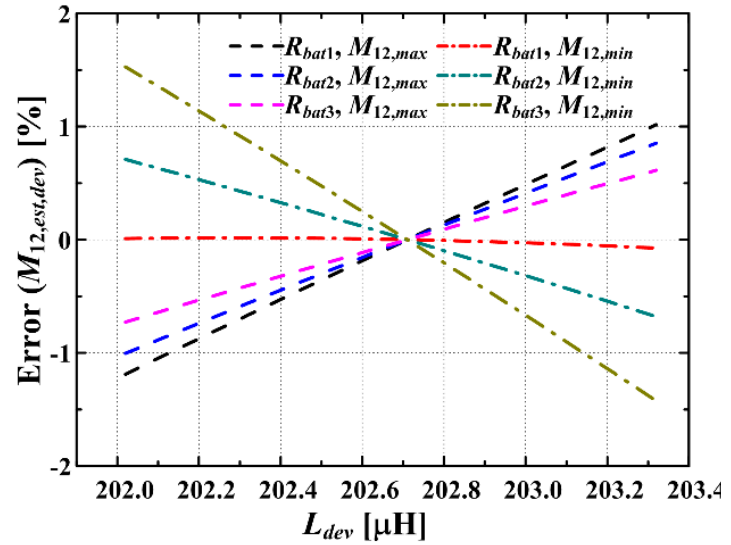

(b)

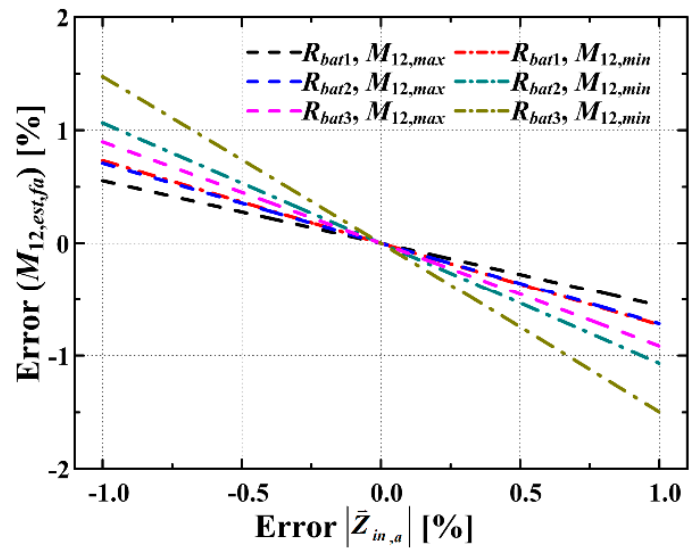

(d)

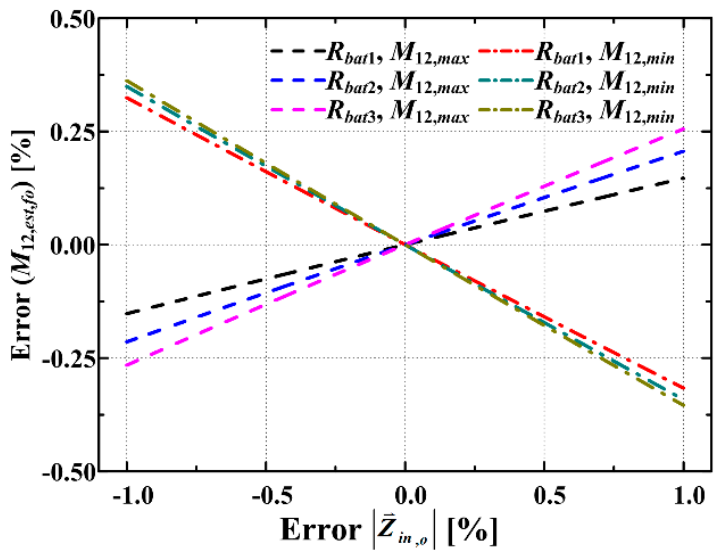

(f)

Figure 14. Error analyses (a) of $R_{b a t, \text { est }}$ with inductance deviation, (b) of $M_{12, e s t}$ with inductance deviation, (c) of $R_{b a t, e s t}$ with measurement error at $f_{a},(\mathbf{d})$ of $M_{12, \text { est }}$ with measurement error at $f_{a}$, (e) of $R_{\text {bat, est }}$ with measurement error at $f_{o}$, and (f) of $M_{12, \text { est }}$ with measurement error at $f_{o}$.

At first, the coil alignment of the proposed estimation method was verified in the rage of $h=$ $5-7 \mathrm{~cm}$ at $v=0 \mathrm{~cm}$ and $v=0-6 \mathrm{~cm}$ at $v=5 \mathrm{~cm}$. In this misalignment range of coils, the self-inductance of $L_{1}$ and $L_{2}$ was changed according to the effect of the magnetic field between coils. The variation range of $L_{1}=202.01-203.41 \mu \mathrm{H}$, and $L_{2}=201.50-202.94 \mu \mathrm{H}$ in $M_{12}=38.66-59.18 \mu \mathrm{H}$. In this error analysis, 
according to the $L_{d e v}$, the simulation parameters were set as $L_{1}=L_{2}=202.71 \mu \mathrm{H}, C_{1}=C_{2}=49.97 \mathrm{nF}$, $R_{\text {in }}=12 \mathrm{~m} \Omega, R_{1}=252 \mathrm{~m} \Omega$, and $R_{2}=248 \mathrm{~m} \Omega$. Then, the $L_{d e v}$ was equivalently set between $L_{1}$ and $L_{2}$ as $L_{\text {dev }}=L_{1, \text { dev }}=L_{2, \text { dev }}=202.02-203.41 \mu \mathrm{H}, R_{\text {bat } 1}=15 \Omega, R_{\text {bat } 2}=20 \Omega, R_{\text {bat } 3}=25 \Omega, M_{12, \max }=59.18 \mu \mathrm{H}$, and $M_{12, \min }=38.66 \mu \mathrm{H}$. The Error $\left|\vec{Z}_{i n, a}\right|$ and Error $\left|\vec{Z}_{i n, o}\right|$ were set to zero in this analysis, and only $L_{d e v}$ was considered. As a result, the $\operatorname{Error}\left(R_{b a t, e s t, d e v}\right)$ and $\operatorname{Error}\left(M_{12, e s t, d e v}\right)$ increased as $R_{b a t}$ decreased at $M_{12, \max }$ and $R_{b a t}$ increased at $M_{12, \min }$ (Figure 14a,b). Also, the Error $\left(R_{b a t, e s t, d e v}\right)$ and $\operatorname{Error}\left(M_{12, e s t, d e v}\right)$ due to the variation of $R_{b a t}\left(R_{b a t 1}-R_{b a t 3}\right)$ were more sensitive at $M_{12, \min }$ than $M_{12, \max }$.

Secondly, the proposed estimation method measures the $\left|\vec{Z}_{\text {in,a,measure }}\right|$ and $\left|\vec{Z}_{\text {in,o,measure }}\right|$, and the Error $\left|\vec{Z}_{i n, a}\right|$ and Error $\left|\vec{Z}_{i n, o}\right|$ have an effect on the accuracy of the estimation. In this error analysis, according to the Error $\left|\vec{Z}_{i n, a}\right|$ and Error $\left|\vec{Z}_{i n, o}\right|, \operatorname{Error}\left(R_{b a t, e s t, f a}\right), \operatorname{Error}\left(M_{12, e s t, f a}\right), \operatorname{Error}\left(R_{b a t, e s t, f 0}\right)$, and $\operatorname{Error}\left(M_{12, e s t, f o}\right)$ were analyzed under the $\pm 1 \%$ variation of Error $\left|\vec{Z}_{i n, a}\right|$ and Error $\left|\vec{Z}_{i n, o}\right|$, and the simulation parameters were equivalently set as the error analysis of Equations (25) and (26). The Error $\left(R_{b a t, e s t, d e v}\right)$ and $\operatorname{Error}\left(M_{12, e s t, d e v}\right)$ were set to zero in this analysis. In the $\operatorname{Error}\left|\vec{Z}_{i n, a}\right|$, the $\operatorname{Error}\left(R_{b a t, e s t, f a}\right)$ and $\operatorname{Error}\left(M_{12, e s t, f a}\right)$ increased as $R_{b a t}$ increased, and were larger at $M_{12, \min }$ than $M_{12, \text { max }}$ in the same $R_{b a t}$ (Figure $14 \mathrm{c}, \mathrm{d})$. In the Error $\left|\vec{Z}_{i n, o}\right|$ at $M_{12, \max }$, the $\operatorname{Error}\left(R_{\text {bat }, e s t, f_{0}}\right)$ and $\operatorname{Error}\left(M_{12, e s t, f o}\right)$ increased as $R_{b a t}$ increased. At $M_{12, \text { min }}$, the Error $\left(R_{b a t, e s t, f o}\right)$ increased as $R_{b a t}$ decreased, and $\operatorname{Error}\left(M_{12, e s t, f o}\right)$ increased as $R_{b a t}$ increased (Figure 14e,f). Overall, the Error $\left|\vec{Z}_{i n, a}\right|$ had more impact on the accuracy of proposed estimation method than the Error $\left|\vec{Z}_{i n, o}\right|$.

In conclusion, the errors of estimation results were $<3 \%$ in Equations (25), (29), and (31), and $<1.5 \%$ in Equations (26), (30) and (32). Also, Equations (25) and (26) (Figure 14a,b) were more sensitive to the variation of $R_{b a t}$ and $M_{12}$ than Equations (29)-(32) (Figure 14c-f). In the practical applications, the proposed controller (Figure 6) includes the protection function to limit the range of coil alignment as $M_{12, e s t}<M_{12 \text {,limit }}$, and the auxiliary positioning device can be introduced to minimize the inductance deviation.

\section{Conclusions}

This paper presents a wireless battery charging circuit that uses a new load estimation method. The proposed method estimates $R_{L}, M_{12}, V_{b a t}$, and $I_{b a t}$ without any wireless communication by using a simple peak detection circuit to sense the peak current of the transmitter coil; it samples this peak current as a DC value. After the peak current values are sampled at resonant frequency $f_{o}$ and auxiliary frequency $f_{a}$, the estimation is performed by using the magnitude of the input impedance. Thus, this method does not need a high sampling frequency to detect the AC voltage and the current of the transmitter coil. When the proposed WPT circuit is operated to charge a battery pack, the circuit uses the proposed load estimation method and phase $\phi$ control of the full-bridge inverter to regulate the output current and voltage. A prototype circuit to charge a $48-\mathrm{V}$ battery pack was tested under the various load resistance and coil alignment conditions. Then, the errors of estimation results due to the inductance variation and measurement error were analyzed. Finally, all experimental and simulation results indicated that the proposed method is well suited to control the WPT battery charging circuit efficiently.

Author Contributions: S.-W.L. developed the circuit and load estimation method, constructed the hardware prototype, and conducted the experiments. Y.-G.C. and J.-H.K. supported the experiments and analyzed the experimental results. B.K. provided guidance and key suggestions for this study. 
Funding: This research was supported by the MSIT (Ministry of Science and ICT), Korea, under the "ICT Consilience Creative program" (IITP-2019-2011-1-00783) supervised by the IITP (Institute for Information \& communications Technology Promotion).

Conflicts of Interest: The authors declare no conflict of interest.

\section{Nomenclature}

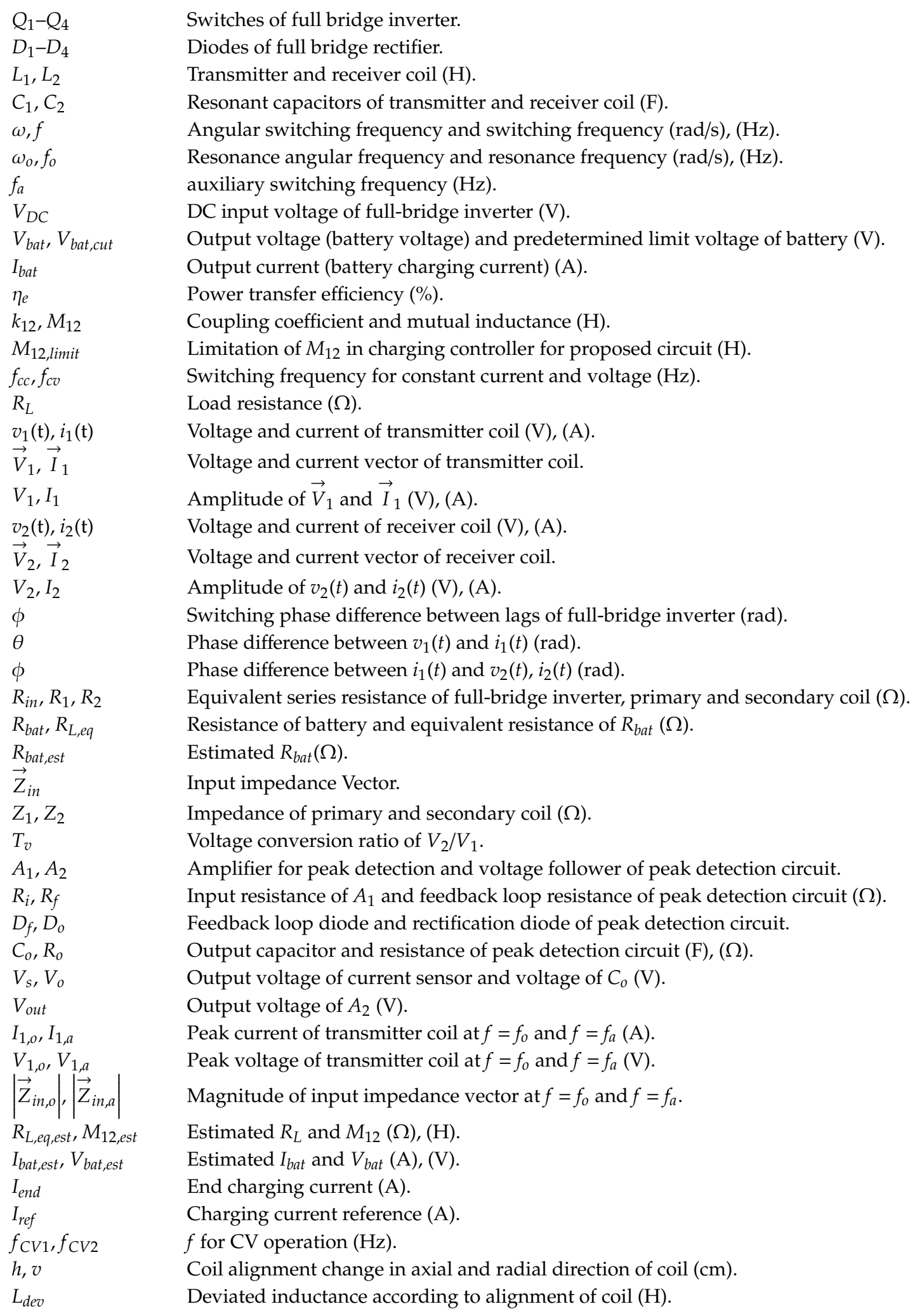




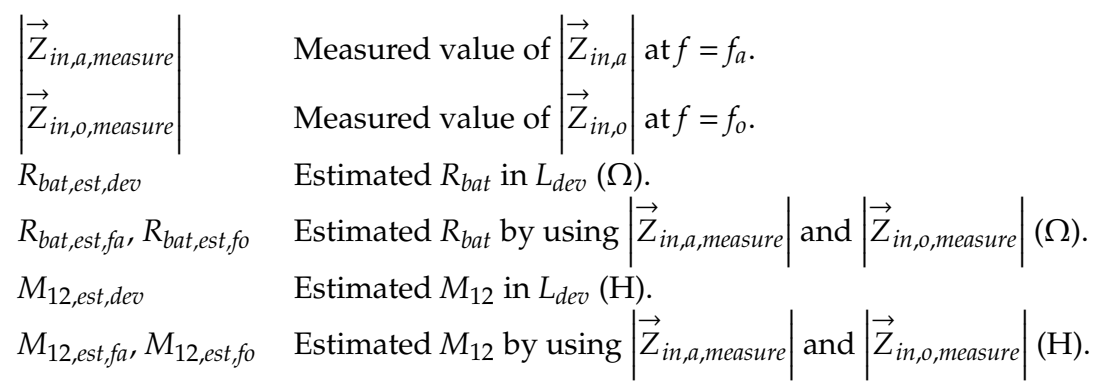

\section{References}

1. Marco, D.D.; Dolara, A.; Longo, M. A review on dynamic wireless charging systems. In Proceedings of the IEEE Milan PowerTech, Milan, Italy, 23-27 June 2019.

2. Dolara, A.; Leva, S.; Longo, M.; Dezza, F.C.; Mauri, M. Coil design and magnetic shielding of a resonant wireless power transfer system for electric vehicle battery charging. In Proceedings of the IEEE 6th International Conference on Renewable Energy Research and Applications (ICRERA), San Diego, CA, USA, 5-8 November 2017; pp. 200-205.

3. Shin, J.; Shin, S.; Kim, Y.; Ahn, S.; Lee, S.; Jung, G.; Jeon, S.J.; Cho, D.H. Design and implementation of shaped magnetic-resonance-based wireless power transfer system for roadway-powered moving electric vehicles. IEEE Trans. Ind. Electron. 2015, 61, 1179-1192. [CrossRef]

4. Silay, K.M.; Dehollain, C.; Declercq, M. Inductive power link for a wireless cortical implant with biocompatible packaging. In Proceedings of the IEEE SENSORS Conference, Kona, HI, USA, 1-4 November 2010; pp. 94-98.

5. Stielau, O.H.; Covic, G.A. Design of loosely coupled inductive power transfer systems. In Proceedings of the International Conference on Power System Technology, Perth, Australia, 4-7 December 2000; pp. 85-90.

6. Wang, C.S.; Stielau, O.H.; Covic, G.A. Design considerations for a contactless electric vehicle battery charger. IEEE Trans. Ind. Electron. 2005, 52, 1308-1314. [CrossRef]

7. Chopra, S.; Bauer, P. Analysis and design considerations for a contactless power transfer system. In Proceedings of the 33rd International Telecommunications Energy Conference (INTELEC), Amsterdam, The Netherlands, 9-13 October 2011; pp. 1-6.

8. Bosshard, R.; Kolar, J.W.; Mühlethaler, J.; Stevanović, I.; Wunsch, B.; Canales, F. Modeling and $\eta$ - $\alpha$-pareto optimization of inductive power transfer coils for electric vehicles. IEEE J. Emerg. Sel. Top. Power Electron. 2015, 3, 50-64. [CrossRef]

9. Zheng, C.; Lai, J.S.; Chen, R.; Faraci, W.E.; Zahid, Z.U.; Gu, B.; Zhang, L.; Lisi, G.; Anderson, D. High-efficiency contactless power transfer system for electric vehicle battery charging application. IEEE J. Emerg. Sel. Top. Power Electron. 2015, 3, 65-74. [CrossRef]

10. Tran, D.H.; Vu, V.B.; Choi, W. Design of a high-efficiency wireless power transfer system with intermediate coils for the on-board chargers of electric vehicles. IEEE Trans. Power Electron. 2018, 33, 175-187. [CrossRef]

11. Qu, X.; Han, H.; Wong, S.C.; Tse, C.K.; Chen, W. Hybrid IPT topologies with constant current or constant voltage output for battery charging applications. IEEE Trans. Power Electron. 2015, 30, 6329-6337. [CrossRef]

12. Mai, R.; Chen, Y.; Li, Y.; Zhang, Y.; Cao, G.; He, Z. Inductive power transfer for massive electric bicycles charging based on hybrid topology switching with a single inverter. IEEE Trans. Power Electron. 2017, 32, 5897-5906. [CrossRef]

13. Li, S.; Mi, C.C. Wireless power transfer for electric vehicle application. IEEE J. Emerg. Sel. Top. Power Electron. 2015, 3, 4-17.

14. Song, K.; Li, Z.; Jiang, J.; Zhu, C. Constant current/voltage charging operation for series-series and series-parallel compensated wireless power transfer systems employing primary-side controller. IEEE Trans. Power Electron. 2018, 33, 8065-8080. [CrossRef]

15. Yin, J.; Lee, C.K.; Parisini, T.; Hui, S.Y. Front-End Monitoring of Multiple Loads in Wirelss Power Transfer Systems without Wirelss Communication Systems. IEEE Trans. Power Electron. 2016, 31, 2510-2517. [CrossRef]

16. Yin, J.; Lee, C.K.; Hui, S.Y. A systematic approach for load monitoring and power control in wireless power transfer systems without any direct output measurement. IEEE Trans. Power Electron. 2015, 30, 1657-1667. [CrossRef] 
17. Su, Y.G.; Zhang, Y.H.; Wang, Z.H.; Hu, A.P.; Chen, L.; Sun, Y. Steady-state load identification method of inductive power transfer system based on switching capacitors. IEEE Trans. Power Electron. 2015, 30, 6349-6355. [CrossRef]

18. Yin, J.; Parisini, T.; Hui, S.Y. Front-end monitoring of the mutual inductance and load resistance in a series-series compensated wireless power transfer system. IEEE Trans. Power Electron. 2016, 31, 7339-7352. [CrossRef]

19. Wang, Z.H.; Li, Y.P.; Tang, C.S.; Lv, X. Load detection model of voltage-fed inductive power transfer system. IEEE Trans. Power Electron. 2013, 28, 5233-5243. [CrossRef]

20. Sedra, S.; Smith, K.C. Microelectronic Circuits, 5th ed.; Oxford University Press: Oxford, UK, 1998.

C 2019 by the authors. Licensee MDPI, Basel, Switzerland. This article is an open access article distributed under the terms and conditions of the Creative Commons Attribution (CC BY) license (http://creativecommons.org/licenses/by/4.0/). 